\title{
Incidência de fungos em grãos de milho em função de diferentes épocas de aplicação foliar de fungicida ${ }^{1}$
}

\author{
Josemar Stefanello², Lilian Maria Arruda Bachi², \\ Walber Luiz Gavassoni² ${ }^{2}$ Lúcia Mayumi Hirata ${ }^{2}$, Bruno Cezar Álvaro Pontim ${ }^{2}$
}

\begin{abstract}
Incidence of fungus in maize grains according to different times of fungicide foliar application

In the maize crop, ear rottenness caused by fungi stands out for affecting harvested grain yield and quality, especially due to the formation of "rotten grains". In addition to this kind of deterioration, which results in a nutritional loss, some fungi may cause contamination by producing mycotoxins. This study aimed at evaluating the influence of the azoxystrobin + ciproconazole fungicide foliar application and application times in the presence of fungi, in grains harvested from three hybrids, in two sowing seasons (summer cropping and intercropping). Field trials were carried out in a randomized blocks design, with treatments consisting of sowing seasons $\mathrm{x}$ hybrids $\mathrm{x}$ application times $(2 \times 3 \times 5)$. The fungicides were applied at the V8, V8 + pre-tasseling, pre-tasseling and R1 stages, plus a control with no application. Manual harvest was carried out in the plots and grain samples from each plot were submitted to the sanitary quality analysis, by using the filter paper method (Blotter test), with freezing. The two foliar applications (V8 + pre-tasseling) of the azoxystrobin + cyproconazole $\left(300.0 \mathrm{~mL} \mathrm{ha}^{-1}+0.5 \%\right.$ mineral oil) fungicide, or one pre-tasseling application, resulted in lower incidence of the Fusarium sp. fungus, in grains harvested in both sowing seasons.
\end{abstract}

KEY-WORDS: Zea mays L.; Fusarium sp.; Penicillium sp.; Aspergillus sp.; rotten grains.

\section{INTRODUÇÃO}

O milho (Zea mays L.) é um dos cereais mais cultivados no mundo, com destaque para o papel que cumpre na cadeia alimentar e seu valor agronômico no sistema plantio direto. No Brasil, na safra agrícola 2010/2011, a área cultivada foi de 13,8 milhões de hectares, com produção de 57,4 milhões de toneladas de grãos (Conab 2012).

Ao longo dos últimos anos, tem sido observado um avanço de doenças, nessa cultura, como con-

\section{RESUMO}

Na cultura do milho, as podridões de espigas causadas por fungos destacam-se por resultarem em perdas na produção e na qualidade dos grãos colhidos, principalmente devido à formação de "grãos ardidos". Além desta deterioração, que ocasiona perda nutricional, alguns fungos podem provocar contaminação, pela produção de micotoxinas. Este estudo objetivou avaliar a influência da aplicação do fungicida azoxistrobina + ciproconazol via foliar e de épocas de aplicação na presença de fungos, em grãos colhidos de três híbridos, em duas épocas de semeadura (safra de verão e safrinha). Foram realizados ensaios de campo, dispostos em delineamento de blocos ao acaso, com tratamentos constituindo-se da combinação de épocas de semeadura $\mathrm{x}$ híbridos $\mathrm{x}$ épocas de aplicação $(2 \times 3 \times 5)$. As aplicações dos fungicidas foram realizadas nos estádios $\mathrm{V} 8, \mathrm{~V} 8$ + pré-pendoamento, pré-pendoamento e R1, mais uma testemunha sem aplicação. Realizou-se a colheita manual das parcelas, e amostras de grãos de cada parcela foram submetidas à análise de qualidade sanitária, pelo método do papel filtro (Blotter test), com congelamento. A realização de duas aplicações (V8+ pré-pendoamento), via foliar, do fungicida azoxistrobina + ciproconazol (300,0 $\mathrm{mL} \mathrm{ha}^{-1}+0,5 \%$ de óleo mineral), ou uma aplicação em pré-pendoamento, resultou em menor incidência do fungo Fusarium sp., nos grãos colhidos nas duas épocas de semeadura.

PALAVRAS-CHAVE: Zea mays L.; Fusarium sp.; Penicillium sp.; Aspergillus sp.; grãos ardidos.

sequência do estreitamento das relações patógeno-hospedeiro-ambiente. Neste sentido, a aplicação de fungicida, via foliar, torna-se uma estratégia a mais, no manejo da cultura, com o propósito de assegurar o potencial produtivo do híbrido, além da qualidade dos grãos. Os fungicidas registrados para a cultura proporcionam maior sanidade das plantas, reduzindo a colonização dos patógenos causadores de grãos ardidos (Duarte et al. 2009).

Grãos ardidos constituem-se em um dos principais problemas na qualidade dos grãos de milho,

1. Trabalho recebido em jun./2012 e aceito para publicação em dez./2012 (nº registro: PAT 19153).

2. Universidade Federal da Grande Dourados (UFGD), Faculdade de Ciências Agrárias, Dourados, MS, Brasil.

E-mails: josemarstefanello@hotmail.com, lilianbacchi@ufgd.edu.br, walber.gavassoni@ufgd.edu.br, luciahirata2011@gmail.com, brunopontim@ufgd.edu.br. 
devido à possibilidade da presença de micotoxinas, tais como aflatoxinas, fumonisinas, zearalenona, toxina T-2 e ocratoxina, dentre outras. A perda qualitativa por grãos ardidos é motivo de desvalorização do produto e uma ameaça à saúde dos rebanhos e humana (Pinto 2001).

Grãos de milho podem ser afetados por fungos em duas etapas específicas: na pré-colheita (podridões fúngicas de espigas, com a formação de grãos ardidos) e na pós-colheita, durante o beneficiamento, armazenamento e transporte (grãos mofados ou embolorados) (Pinto 2005). A podridão destaca-se, no mundo, como uma das mais importantes doenças que atacam a cultura do milho, por reduzir a produção e a qualidade dos grãos (Costa et al. 2005, Viana 2009).

Os grãos ardidos são o reflexo das podridões de espigas, causadas, principalmente, pelos fungos presentes no campo (Pinto 2005, Juliatti et al. 2006 e 2007). Estes fungos podem ser divididos em dois grupos: os que apenas produzem grãos ardidos e os que, além da produção de grãos ardidos, são exímios produtores de toxinas, denominadas micotoxinas (Pinto 2005). Os principais danos causados pelo ataque são a descoloração dos grãos e redução nos conteúdos de carboidratos, proteínas e açúcares totais (Costa et al. 2005).

É importante ressaltar que a presença do fungo toxigênico não implica, necessariamente, na produção de micotoxinas, as quais estão intimamente relacionadas à capacidade de biossíntese do fungo e das condições ambientais predisponentes, como, em alguns casos, a alternância entre temperaturas diurna e noturna (Pinto 2005).

Jay (2005) define micotoxinas como sendo metabólitos secundários, produzidos por fungos filamentosos. Os metabólitos primários são essenciais ao desenvolvimento e crescimento, e os secundários são formados durante o final da fase exponencial de crescimento e não possuem significância aparente.
Em geral, os metabólitos secundários parecem ser formados quando grandes quantidades de precursores de metabólitos primários, tais como aminoácidos, acetato, piruvato e outros, são acumulados (Freire 2007).

Diante do exposto, o presente trabalho objetivou verificar a influência da aplicação do fungicida azoxistrobina + ciproconazol, via foliar, e de épocas de aplicação, na presença de fungos, em grãos colhidos de três híbridos de milho, em duas épocas de semeadura.

\section{MATERIAL E MÉTODOS}

O experimento de campo foi realizado em duas épocas de semeadura (safra de verão e safrinha), sob condições de milho de sequeiro. Na safra de verão (2010/2011), o ensaio foi realizado na Unidade Experimental da Faculdade de Ciências Agrárias da Universidade Federal da Grande Dourados, Doura-

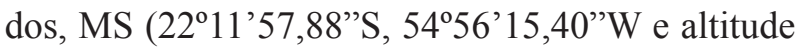
de 455,0 m). Na safrinha de 2011, foi utilizada uma área experimental localizada na Fazenda Jatobá, no município de Rio Brilhante, MS (21\%47'40,3”S, $54^{\circ} 37^{\prime} 4,36^{\prime \prime} \mathrm{W}$ e altitude de $331,0 \mathrm{~m}$ ). As especificações dos ensaios estão expostas na Tabela 1.

Para a implantação da cultura, na safra de verão, o preparo do solo constituiu-se de uma gradagem média e outra leve, na véspera da implantação do ensaio. No ensaio de safrinha, realizou-se semeadura direta sobre restos da cultura da soja (variedade BMX Potência RR).

A semeadura foi efetuada de forma mecanizada, com uma semeadora-adubadora de quatro linhas, sendo semeadas sete sementes por metro linear de sulco, à profundidade de, aproximadamente, $5,0 \mathrm{~cm}$, e o espaçamento entre as linhas de cultivo foi de $90,0 \mathrm{~cm}$. Realizou-se adubação com $300,0 \mathrm{~kg} \mathrm{ha}^{-1}$ da fórmula 08-20-20. As sementes utilizadas foram

Tabela 1. Caracterização dos locais dos ensaios e suas respectivas datas de semeadura e colheita.

\begin{tabular}{cclcc}
\hline \multirow{2}{*}{ Local } & Época de & \multirow{2}{*}{ Híbrido } & Data \\
\cline { 3 - 5 } & semeadura & Celeron TL & $13 / 10 / 2011$ & Colheita \\
\hline \multirow{2}{*}{ Dourados (MS) } & \multirow{3}{*}{ Safra } & Penta TL & $13 / 10 / 2011$ & $24 / 03 / 2011$ \\
& & Status TL & $13 / 10 / 2011$ & $24 / 03 / 2011$ \\
\hline \multirow{3}{*}{ Rio Brilhante (MS) } & & Celeron TL & $26 / 02 / 2011$ & $19 / 07 / 2011$ \\
& \multirow{2}{*}{ Safrinha } & Penta TL & $26 / 02 / 2011$ & $29 / 07 / 2011$ \\
& & Status TL & $26 / 02 / 2011$ & $29 / 07 / 2011$ \\
\hline
\end{tabular}


tratadas com inseticida Tiametoxam + fungicida Metalaxil-M + Fludioxonil, na dose de 100,0 $\mathrm{mL} \mathrm{ha}^{-1}$ de cada produto, para todos os híbridos, em todos os ensaios, como forma de prevenção ao ataque das principais pragas iniciais da cultura.

Quando as plantas apresentavam a terceira folha totalmente aberta, realizou-se o desbaste das plantas, nas parcelas, deixando-se 4,5 plantas por metro linear, no ensaio de verão, e 4,1 plantas por metro linear, no ensaio de safrinha, com o intuito de padronizar a população, em todas as parcelas.

No estádio V4 da cultura, realizou-se adubação de cobertura com $85,0 \mathrm{~kg} \mathrm{ha}^{-1}$ de nitrogênio, na forma de ureia. Para o controle de ervas daninhas, foram efetuadas capinas manuais, de acordo com o crescimento das ervas. Para o controle de lagartas, forma utilizados híbridos com a tecnologia Agrisure $\mathrm{TL}^{\circledR}$, que confere tolerância à lagarta do cartucho, principal praga desfolhadora da cultura.

$\mathrm{O}$ delineamento experimental utilizado foi o de blocos casualizados, com cinco tratamentos para cada híbrido e quatro repetições. Nas duas épocas de semeadura, as parcelas foram constituídas por quatro linhas de $6,0 \mathrm{~m}$, totalizando $21,6 \mathrm{~m}^{2}$, nas quais foram consideradas, como área útil, apenas as duas linhas centrais com 5,0 m, desprezando-se uma linha de cada lado e $0,5 \mathrm{~m}$ de cada extremidade da parcela, totalizando, desta forma, área útil de $9,0 \mathrm{~m}^{2}$.

Os tratamentos utilizados basearam-se na aplicação de $300,0 \mathrm{~mL} \mathrm{ha}^{-1}$ do fungicida azoxistrobina + ciproconazol (Priori Xtra ${ }^{\circledR}$ ) mais $600,0 \mathrm{~mL} \mathrm{ha}^{-1} \mathrm{de}$ óleo mineral $\left(\right.$ Nimbus $\left.^{\circledR}\right)$, em diferentes épocas de aplicação, sendo T1: testemunha sem aplicação de fungicida; T2: uma aplicação no estádio V8; T3: uma aplicação no estádio V8 e outra aplicação sequencial no estádio de pré-pendoamento; T4: uma aplicação no estádio de pré-pendoamento; T5: uma aplicação no estádio R1. Para a aplicação dos tratamentos, utilizou-se um pulverizador costal pressurizado com $\mathrm{CO}_{2}$, com bico tipo leque e volume de calda de $200,0 \mathrm{~L} \mathrm{ha}^{-1}$.

A colheita foi realizada manualmente, por parcela, e as amostras dos grãos colhidos de cada parcela foram submetidas à análise de qualidade sanitária, pelo método do papel filtro (Blotter test), com congelamento. As sementes foram distribuídas no interior de caixas de germinação, contendo uma camada de três folhas de papel filtro umedecidas em água destilada, na quantidade de 20 sementes por caixa de germinação e cinco caixas por parcela. Em seguida, as caixas de germinação foram armazenadas por 24 horas, em câmara de incubação (BOD), à temperatura de $20 \pm 2^{\circ} \mathrm{C}$, com fotoperíodo de 12 horas de luz/ 12 horas de escuro, sendo, posteriormente, submetidas ao congelamento em freezer, por um período de 24 horas. Decorrido este tempo, as caixas foram acondicionadas, novamente, em câmara de incubação (BOD), à temperatura de $20 \pm 2^{\circ} \mathrm{C}$, com fotoperíodo de 12 horas de luz/ 12 horas de escuro, por mais cinco dias.

Após sete dias de incubação, as sementes foram examinadas em microscópio estereoscópico, a fim de se realizar a identificação e quantificação de fungos, observando-se suas estruturas reprodutivas (Barnett \& Hunter 1998). Foram calculadas as percentagens de sementes que apresentavam cada um dos gêneros de fungos identificados.

Os dados foram transformados para arco seno $\sqrt{ } \mathrm{x} / 100$ e, após as transformações, foram submetidos à análise de variância, pelo teste $\mathrm{F}$. Ao ser constatada diferença significativa, aplicou-se o teste de Duncan, a $5 \%$. Foi considerado o arranjo fatorial $2 \times 3 \times 5$, sendo duas épocas de semeadura (safra e safrinha), três híbridos de milho e cinco tratamentos com fungicida. As análises estatísticas foram realizadas com o auxílio do aplicativo computacional Sanest.

\section{RESULTADOS E DISCUSSÃO}

Observou-se que, para as duas épocas de semeadura, houve grande incidência de Penicillium sp., seguido por Fusarium sp. O mesmo foi verificado por Ramos et al. (2010), que, em levantamento de fungos presentes em grãos ardidos e sementes de milho, observaram alta incidência dos gêneros Fusarium e Penicillium, principalmente na safra de verão. Azevedo et al. (1994) e Orsi et al. (1995) observaram que o gênero mais encontrado no milho recém-colhido foi o Fusarium, seguido por Aspergillus e Penicillium.

$\mathrm{Na}$ análise de variância dos dados, não foi detectado efeito da época de semeadura sobre a incidência de Aspergillus sp. e de Penicillium sp., nos grãos de milho. Houve interação de épocas de semeadura e híbridos, para os fungos Fusarium sp. e Nigrospora sp., sendo a incidência de Fusarium maior em grãos do híbrido Celeron TL, na safra de verão, como também observado por Ramos et al. (2010). No entanto, para o híbrido Status TL, a incidência de Fusarium sp., e também Nigrospora sp., foi maior na safrinha (Tabela 2). 
Tabela 2. Incidência (\%) de fungos nos grãos colhidos na safra 2010/2011 e safrinha 2011, em três híbridos de milho (Dourados, MS, 2012).

\begin{tabular}{|c|c|c|c|c|c|}
\hline \multirow{2}{*}{ Fungos } & \multirow{2}{*}{ Época de semeadura } & \multicolumn{3}{|c|}{ Híbridos } & \multirow{2}{*}{ Média } \\
\hline & & Celeron TL & Penta TL & Status TL & \\
\hline \multirow{3}{*}{ Fusarium sp. } & Safra verão & 27,42 a $\mathrm{A}$ & 24,84 a A & 19,35 b B & $23,87^{\mathrm{ns}}$ \\
\hline & Safrinha & $19,60 \mathrm{~b}$ B & 22,57 a B & 32,18 a A & \multirow[t]{2}{*}{24,78} \\
\hline & Média & 23,51 & 23,71 & 25,77 & \\
\hline \multirow{3}{*}{ Nigrospora sp. } & Safra verão & 0,00 a B & 0,87 a A & $0,00 \mathrm{~b} \mathrm{~B}$ & 0,29 \\
\hline & Safrinha & 0,00 a $\mathrm{C}$ & 0,78 a B & 5,84 a A & \multirow[t]{2}{*}{2,21} \\
\hline & Média & 0,00 & 0,83 & 2,92 & \\
\hline \multirow{3}{*}{ Penicillium sp. } & Safra verão & $95,70^{\mathrm{ns}}$ & $95,70^{\mathrm{ns}}$ & $95,90^{\mathrm{ns}}$ & $95,77^{\mathrm{ns}}$ \\
\hline & Safrinha & 98,35 & 97,85 & 95,95 & \multirow[t]{2}{*}{97,38} \\
\hline & Média & $97,03^{\mathrm{ns}}$ & 96,78 & 95,93 & \\
\hline \multirow{3}{*}{ Aspergillus sp. } & Safra verão & $2,60^{\mathrm{ns}}$ & $1,25^{\mathrm{ns}}$ & $0,55^{\mathrm{ns}}$ & $1,47^{\mathrm{ns}}$ \\
\hline & Safrinha & 2,90 & 0,05 & 0,00 & \multirow[t]{2}{*}{0,98} \\
\hline & Média & $2,75 \mathrm{~A}$ & $0,65 \mathrm{~B}$ & $0,23 \mathrm{~B}$ & \\
\hline
\end{tabular}

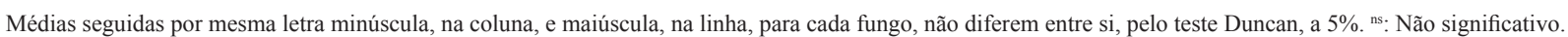

Para o ensaio realizado na safra de verão de 2010/2011, no município de Dourados (MS), constatou-se diferença significativa entre os híbridos, para os fungos Fusarium sp. e Nigrospora sp. (Tabela 2), com o híbrido Status TL diferindo dos demais híbridos e apresentando menor incidência de Fusarium sp., nos grãos colhidos, e Penta TL apresentando maior percentagem de grãos com Nigrospora sp.

No ensaio realizado na safrinha de 2011, no município de Rio Brilhante (MS), novamente, detectou-se diferença estatística entre os híbridos, para os fungos encontrados nos grãos (Tabela 2). O híbrido Status TL apresentou maior incidência dos fungos Fusarium sp. e Nigrospora sp., diferindo, estatisticamente, dos demais híbridos avaliados. O híbrido Penta TL apresentou maior incidência de Nigrospora sp. nos grãos, quando comparado ao Celeron TL.

A incidência de Aspergillus sp. foi significativamente maior em grãos de Celeron TL, sem interação com a época de semeadura (Tabela 2). Este mesmo comportamento de diferentes reações dos híbridos, para os gêneros de fungos encontrados nos grãos colhidos, independentemente da época de semeadura, também foi observado por Mendes et al. (2011), os quais detectaram diferença significativa entre os híbridos de milho, quanto à reação aos fungos Fusarium verticilioides, Stenocarpella maydis e Stenocarpella macrospora.

Não houve efeito da aplicação do fungicida azoxistrobina + ciproconazol, na parte aérea de híbridos de milho, sobre a incidência de Penicillium sp., Aspergillus sp. e Nigrospora sp. nos grãos (Tabela 3).

$\mathrm{Na}$ análise de variância dos dados, detectou-se efeito de tratamentos com fungicida azoxistrobina + ciproconazol na incidência de Fusarium sp., mas não houve interação significativa entre híbridos e tratamentos, ou tratamentos e épocas de semeadura. Considerando-se os três híbridos semeados nas duas

Tabela 3. Incidência (\%) média de fungos (safra e safrinha) em grãos de milho, em relação às diferentes épocas de aplicação do fungicida (Dourados, MS, 2012).

\begin{tabular}{|c|c|c|c|c|}
\hline Épocas de aplicação & Penicillium sp. & Aspergillus sp. & Fusarium sp. & Nigrospora $\mathrm{sp}$. \\
\hline Testemunha & $97,28 \mathrm{a}$ & $0,27 \mathrm{a}$ & $28,60 \mathrm{a}$ & $0,69 \mathrm{a}$ \\
\hline V8 & $97,35 \mathrm{a}$ & $0,11 \mathrm{a}$ & $24,17 \mathrm{bc}$ & $0,48 \mathrm{a}$ \\
\hline $\mathrm{V} 8+$ pré-pendoamento & $97,06 \mathrm{a}$ & $0,38 \mathrm{a}$ & $21,41 \mathrm{c}$ & $0,34 \mathrm{a}$ \\
\hline Pré-pendoamento & $97,79 \mathrm{a}$ & $0,54 \mathrm{a}$ & $21,76 \mathrm{c}$ & $0,59 \mathrm{a}$ \\
\hline $\mathrm{R} 1$ & $98,23 \mathrm{a}$ & $0,32 \mathrm{a}$ & $25,25 \mathrm{~b}$ & $0,51 \mathrm{a}$ \\
\hline C.V. $(\%)$ & 7,61 & 170,62 & 12,39 & 81,40 \\
\hline
\end{tabular}

Médias seguidas por mesma letra minúscula, na coluna, não diferem entre si, pelo teste Duncan, a 5\%. 
épocas (safra e safrinha), nos tratamentos com uma única aplicação no estádio de pré-pendoamento e com duas aplicações (V8 + pré-pendoamento), as incidências de Fusarium sp. foram menores, diferindo da testemunha e de uma única aplicação em R1 (Tabela 3). A aplicação do fungicida em R1, embora tenha diferido dos melhores tratamentos, resultou em incidência deste fungo significativamente menor do que a observada na testemunha.

Duarte et al. (2009) também verificaram redução na incidência de Fusarium moniliforme, em diferentes híbridos de milho, quando submetidos à aplicação foliar do fungicida azoxystrobina + ciproconazol. O mesmo comportamento foi observado por Juliatti et al. (2007), os quais, avaliando o efeito do genótipo na incidência de grãos ardidos de milho sob aplicação foliar de fungicidas, em duas épocas de aplicação, observaram diferença significativa na incidência de Fusarium moniliforme, em função da aplicação de fungicidas via foliar, sendo que o tratamento em que estes autores utilizaram o fungicida azoxystrobina + ciproconazol resultou na menor incidência, com redução de $33 \%$ na infecção. No entanto, estes mesmos autores, também, não encontraram efeitos significativos das épocas de aplicação (45, 45 e 60 DAS), na incidência de Fusarium moniliforme.

Yoshida et al. (2008), avaliando o momento ideal da aplicação de fungicida, para controlar o acúmulo de micotoxinas produzidas pelo gênero Fusarium, na cultura da cevada, concluíram que a aplicação de fungicida reduz o teor de micotoxinas nos grãos colhidos.

Segundo Pinto (2005), entre os fungos de maior importância que atacam a cultura do milho, encontram-se os do gênero Fusarium, não só por causarem doenças em plantas, mas, também, devido ao fato de algumas espécies produzirem micotoxinas. Desta forma, os resultados encontrados neste trabalho podem subsidiar o manejo da cultura, para evitar maiores níveis de contaminação de grãos de milho, pois, além da esperada proteção da área foliar, conferida pela aplicação de fungicidas na parte aérea, também ocorre redução na incidência de Fusarium sp., nos grãos colhidos.

Segundo Bush et al. (2004), além do controle químico para a redução da contaminação por Fusarium e, consequentemente, diminuição da contaminação por micotoxinas, a colheita precoce pode ser empregada como estratégia de controle de contaminação de fumonisinas. De acordo com estes autores, em anos com condições ambientais favoráveis à contaminação por fumonisina, a colheita precoce (superior a 25\% de umidade de grãos) pode ajudar a reduzir o nível de contaminação.

Em razão da crescente preocupação com o aumento de grãos ardidos, na cultura do milho, e, também, com a contaminação de grãos por micotoxinas, estratégias como a utilização de híbridos resistentes, aplicação de fungicidas e colheita precoce, dentre outras medidas, devem ser exploradas, para gerenciar esta doença e reduzir os danos causados.

\section{CONCLUSÕES}

1. A realização de duas aplicações (V8 + pré-pendoamento), ou uma aplicação no pré-pendoamento, via foliar, do fungicida azoxistrobina + ciproconazol (300,0 $\mathrm{mL} \mathrm{ha}^{-1}+0,5 \%$ de óleo mineral) resultou em menor incidência do fungo Fusarium sp., nos grãos colhidos, nas duas épocas de semeadura.

2. A pulverização de plantas de milho com fungicida azoxistrobina + ciproconazol $\left(300,0 \mathrm{~mL} \mathrm{ha}^{-1}+\right.$ $0,5 \%$ de óleo mineral) não resultou em menor incidência de Aspergillus sp. e Penicillium sp. nos grãos.

\section{REFERÊNCIAS}

AZEVEDO, L. G.; GAMBALE, W.; CORRÊA, B. Mycoflora and aflatoxigenic species of Aspergillus spp. isolated from stored maize. Microbiologia, São Paulo, v. 25, n. 1, p. 46-50, 1994.

BARNETT, H. L.; HUNTER, B. B. Illustrated genera of imperfect fungi. 4. ed. St. Paul: American Phytopathological Society, 1998.

BUSH, B. J. et al. Infection and fumonisin production by Fusarium verticillioides in developing maize kernels. Phytopathology, St. Paul, v. 94, n. 1, p. 88-93, 2004.

COMPANHIA NACIONAL DE ABASTECIMENTO (Conab). Levantamento da safra agrícola 2010/2011. 2012. Disponível em: <http://www.conab.gov.br >. Acesso em: 16 fev. 2012.

COSTA, R. V.; CASELA, C. R.; COTA, V. L. Podridões do colmo e das raízes. 2005. Disponível em: <http:// www.agencia.cnptia.embrapa.br/gestor/milho/arvore/ CONTAG01_64_16820051120.html>. Acesso em: 10 maio 2012.

DUARTE, R. P. et al. Comportamento de diferentes genótipos de milho com aplicação foliar de fungicida 
quanto à incidência de fungos causadores de grãos ardidos. Bioscience Journal, Uberlândia, v. 25, n. 4, p. 112-122, 2009.

FREIRE, F. C. O. Micotoxinas: importância na alimentação e na saúde humana e animal. Fortaleza: Embrapa Agroindústria Tropical, 2007.

JAY, J. M. Microbiologia de alimentos. 6. ed. Porto Alegre: Artmed, 2005.

JULIATTI, F. C. et al. Avaliação da incidência de grãos ardidos em genótipos de milho sob aplicação foliar de fungicidas. Fitopatologia Brasileira, Brasília, DF, v. 31, supl., p. 312, 2006.

JULIATTI, F. C. et al. Efeito do genótipo de milho e da aplicação foliar de fungicidas na incidência de grãos ardidos. Bioscience Journal, Uberlândia, v. 23, n. 2, p. 3441, 2007.

MENDES, M. C. et al. Qualidade sanitária de grãos de milho com e sem inoculação a campo dos fungos causadores de podridões de espiga. Ciência e Agrotecnologia, Lavras, v. 35, n. 5, p. 931-939, 2011.

ORSI, R. B.; CORRÊA, B.; POZZI, C. R. Microbiota fúngica em três híbridos de milho recém-colhidos e armazenados. In: SEMINÁRIO SOBRE A CULTURA DO MILHO "SAFRINHA", 3., 1995, Assis. Anais... Assis: Instituto Agronômico de São Paulo, 1995. p. 105-110.
PINTO, N. F. J. de A. Grãos ardidos em milho. Sete Lagoas: Embrapa Milho e Sorgo, 2005. (Circular técnica, 66).

PINTO, N. F. J. de A. Qualidade sanitária de grãos de milho. Sete Lagoas: Embrapa Milho e Sorgo, 2001. (Comunicado técnico, 30).

RAMOS, A. T. M. et al. Levantamento da micoflora presente em grãos ardidos e sementes de milho. Summa Phytopathologica, Botucatu, v. 36, n. 3, p. 257-259, 2010.

VIANA, G. Milho: novos sistemas de produção e busca por maiores produtividades provocam aumento da severidade das doenças. Jornal Eletrônico da Embrapa Milho e Sorgo, Sete Lagoas, nov. 2009. Disponível em: < http:// www.cnpms.embrapa.br/grao/19_edicao/grao_em_grao_ materia_01.htm >. Acesso em: 10 maio 2012.

YOSHIDA, M. et al. Effect of the timing of fungicide application on Fusarium head blight and mycotoxin accumulation in closed-flowering barley. Plant Disease, St. Paul, v. 92, n. 8, p. 1164-1170, 2008. 